\title{
Vom Nutzen guter Benutzbarkeit
}

Nutzerfreundlichkeit oder Usability hat sich zum entscheidenden Faktor für den Erfolg von Hard- und Software entwickelt. Während in den Anfängen Computer nur von Spezialisten bedient wurden, nutzt heute nahezu jeder Arbeitnehmer IT im Berufsleben. Längst kann nicht mehr davon ausgegangen werden, dass jeder Anwender etwas von IT versteht. Für die meisten sind die Programme, die sie alltäglich benutzen, Werkzeuge. Und je einfacher und intuitiver der Umgang mit diesen ist, je zuverlässiger sie tun, was sie sollen, desto höher die Akzeptanz.

Es ist gar nicht lange her, da wurde Usability als eine Art

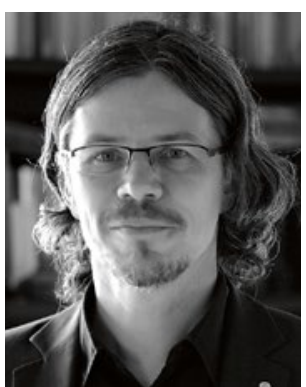

Peter Pagel

Chefredakteur

Designoption betrachtet. Das Programm war fertig und dann machte man es noch ein wenig „hübsch“, damit der Kunde nicht abgeschreckt wird. Echte Nutzerfreundlichkeit sieht anders aus und immer mehr Firmen haben das verstanden. Heute wird Usability zunehmend als etwas gesehen, das man von Anfang an berücksichtigen muss.

Natürlich hat maximale Bequemlichkeit auch ihre Tücken - so stehen etwa größtmögliche Sicherheit und einfachste Bedienbarkeit oft im Konflikt miteinander. Wichtig ist zudem, dass es „die“ beste Usability nicht gibt. Je nach Anwenderkreis bestehen in dieser Hinsicht erhebliche Unterschiede. Alles in allem ist Nutzerfreundlichkeit ein weit komplexeres Thema, als es auf den ersten Blick erscheint, und eines, das sich immer weiterentwickelt. Wer eine Software dauerhaft möglichst nutzerfreundlich machen will, muss am Ball bleiben, denn auch Kundenbedürfnisse und -erwartungen verändern sich.

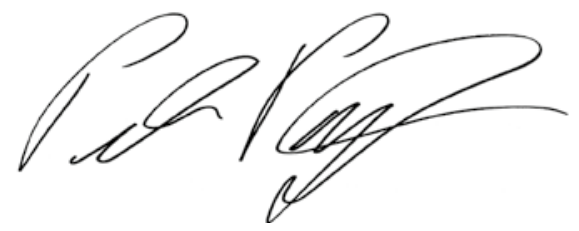

Peter Pagel 